SEMANTIC PRIMING IN BILINGUAL CHILDREN

\title{
Labels or Concepts? The Development of Semantic Networks in Bilingual Two-Year-Olds
}

\author{
Amel Jardak \\ Krista Byers-Heinlein \\ Concordia University
}

\section{Declarations of interest: none}

Correspondence concerning this article should be addressed to Krista Byers-Heinlein, Department of Psychology, Concordia University, Montreal, Quebec, Canada, H2W 2A6, Electronic mail may be sent to k.byers@concordia.ca

Acknowledgments: We thank the members of our laboratories for help in creating stimuli and testing participants, particularly Poppy Wilkinson, Alexandra Polonia, Chelsea da Estrela, Michela Martinello, and Melanie Brouillard. A special thanks to the parents and children who participated in this study. This work was supported by grants from the Natural Sciences and Engineering Council of Canada (402470-2011) and the Fonds de Recherche du Québec - Société et Culture (2012-NP-145009) to KBH, and a fellowship from the Fonds de Recherche du Québec - Société et Culture to AJ. KBH holds the Concordia University Research Chair in Bilingualism.

Jardak, A., \& Byers-Heinlein, K. (2019). Labels or concepts? The development of semantic networks in bilingual two-year-olds. Child Development, 90(2), e212-e229.

https://doi.org/10.1111/cdev.13050 


\begin{abstract}
The adult lexicon links concepts and labels with related meanings (e.g. dog-cat). How do children's encounters with concepts versus labels contribute to semantic development? Three studies investigated semantic priming in 40 monolinguals and 32 bilinguals, who have similar experience with concepts, but different experience with labels (i.e. monolinguals hear "dog”, bilinguals hear "dog” and "chien"). Similarities in performance across monolinguals and bilinguals at age 24 months, as well as across bilinguals' two languages at age 30 months, support the position that encounters with concepts contribute more to early semantic development than encounters with labels. Findings also suggest that the effects of semantic priming are challenging to observe at 24 months, but are strong in bilinguals by age 30 months.
\end{abstract}

Keywords: bilingualism, children, priming, language dominance, semantic development, lexicosemantic networks 


\section{SEMANTIC PRIMING IN BILINGUAL CHILDREN}

Labels or Concepts? The Development of Semantic Networks in Bilingual Two-Year-Olds

As their mental lexicon grows, children are faced with the task of organizing the representations of different words and concepts they learn. Ultimately, they must establish adultlike semantic networks where words and concepts with related meanings are linked together (Beckage, Smith, \& Hills; 2011; Cancho \& Solé, 2001; Collins \& Loftus, 1975; Hills, Maouene, Maouene, Sheya, \& Smith, 2009; Steyvers \& Tenenbaum, 2005). Bilingual children have the more complex task of organizing two sets of labels as they encounter one set of concepts. This unique situation makes bilinguals an ideal population to better understand how experience with labels versus concepts contributes to the early development of semantic networks. Little is currently known about how semantic networks develop in bilingual children. When do bilingual children start associating words and concepts that have related meanings, both within and across their languages? How do these associations develop and how is this development affected by bilinguals' unique language-learning environment?

Studies using priming tasks have begun to reveal when and how semantic networks form in monolingual children (e.g., Arias-Trejo \& Plunkett, 2009; Mani \& Plunkett, 2010, 2011; Styles \& Plunkett, 2011). By age 21-24 months, monolinguals learning British English look correctly to a labeled picture when it is preceded by a related prime (“I have a dog! Cat!"), but perform at chance when it is preceded by an unrelated prime ("I have a boot! Cat!") (Arias-Trejo \& Plunkett 2009; 2013). Priming based on both associative relations (e.g., dog-bone) and taxonomic relations (e.g., dog-cat) has been observed in 24-month-olds, but not 21-month-olds (Arias-Trejo \& Plunkett, 2013). Eighteen-month-olds also do not show this priming effect: they look accurately at a labeled picture whether the prime is related or unrelated to it (Arias-Trejo \& Plunkett, 2009; Styles \& Plunkett, 2009). Further, in auditory-only procedures, 24-month-old 


\section{SEMANTIC PRIMING IN BILINGUAL CHILDREN}

American English monolinguals pay more attention when hearing pairs of unrelated words (dogjuice) than pairs of related words (dog-kitty) (Willits, Wojcik, Seidenberg, \& Saffran, 2013).

This suggests that, unlike 18-month-olds, 24-month-old English monolinguals organize their lexicon in a way that facilitates the recognition of words with related meanings. While these studies document the timing of emergence of semantic networks in monolinguals, and the types of associations that are eventually in place, they do not address mechanisms underlying changes in the nature of the lexicon from 18 to 24 months and beyond. Further, semantic priming studies have been primarily conducted with English-learning monolinguals, with little research on other populations of learners.

\section{Bilingual language development}

Much less is known about the development of bilingual children's semantic system (DeAnda, Poulin-Dubois, Zesiger, \& Friend, 2016). There are some similarities between bilinguals and monolinguals which could suggest that they develop semantic networks in a similar timeframe. Bilingual and monolingual infants reach language milestones at around the same ages (Pearson \& Fernández, 1994; Werker \& Byers-Heinlein, 2008). For instance, they show similar timing in the ability to associate words and objects (Byers-Heinlein, Fennell, \& Werker, 2013). Also, when both their languages are considered, some studied have indicated that bilingual infants and toddlers understand and produce words at the same rate as their monolingual peers (Core, Hoff, Rumiche, \& Señor, 2013; Pearson, Fernández, \& Oller, 1993). However, more recent work with larger samples has indicated that bilinguals are initially slower to learn to name concepts in their environments, although the mechanisms by which they add new words appear to be similar to those that underlie vocabulary growth in monolinguals (Bilson, Yoshida, Tran, Woods, \& Hills, 2015; Hills et al., 2009). 


\section{SEMANTIC PRIMING IN BILINGUAL CHILDREN}

Nonetheless, monolinguals and bilinguals differ importantly in their experience with labels and concepts. For monolinguals, labels and concepts occur in roughly one-to-one correspondence: the word "dog" labels the concept $d o g$. However, bilinguals learn two labels for each concept (one in each language, known as translation equivalents): for a French-English bilingual, both the words "dog" and "chien" label the concept $d o g$. Bilingual children's knowledge of translation equivalents increases proportionately as their vocabularies grow (Legacy, Zesiger, Friend, \& Poulin-Dubois, 2015; Legacy et al., 2016), and there is evidence that learning a word in one language facilitates learning its translation equivalent (Bilson et al., 2015). Yet, these divergent experiences between monolinguals and bilinguals have been shown to affect some aspects of development. For example, monolingual infants assume each object has a single label, while bilinguals do not as readily make the same assumption (Byers-Heinlein, 2017; Byers-Heinlein \& Werker, 2009; 2013; Houston-Price, Caloghiris, \& Raviglione, 2010). This raises the question of how monolingual versus bilingual experience also impacts the development of semantic networks. The answer to this question depends on whether early semantic development reflects children's experience with particular labels (which differs between monolinguals and bilinguals due to translation equivalents) or reflects children's experience with particular concepts (which is similar across monolinguals and bilinguals).

\section{Two accounts of semantic development}

Laboratory studies using small artificial lexicons have provided some initial evidence of the role of encounters with concepts (hereafter the Concepts Account) versus encounters with labels (hereafter the Labels Account) in the development of semantic networks. For example, Wojcik \& Saffran (2013) taught 26-28-month-old children four novel words. The words were presented in a quasi-random order, but their referents could be grouped into two visually similar 


\section{SEMANTIC PRIMING IN BILINGUAL CHILDREN}

pairs. At test, children looked longer when they heard an auditory-only stream that referred to two similar objects rather than a stream that referred to two dissimilar objects. This indicated that, even in absence of a temporal relation between the words, children encoded the relation between the perceptually similar objects. These findings can be taken in support of the Concepts Account. In another study, Wojcik \& Saffran (2015) exposed 26-28 month-old children to four novel words embedded in familiar English sentence frames (e.g., "The tursey broke the pif. The coro opened the blicket."). Children readily encoded the relation between the word pairs that occurred in the same sentence (e.g. tursey-pif), but only those with strong grammatical knowledge also encoded the relation between words that occurred in the same grammatical position across different sentences (e.g. tursey-coro). These findings suggest that it is the temporal co-occurrence of particular words within a sentence that best promoted children's encoding of their relation, supporting the Labels Account, although conceptual information from grammatical position might play a larger role for more advanced learners.

While studies of artificial lexicons provide some insight into what experiences drive the development of semantic networks, it is difficult to know how much these results generalize to language acquisition in the real world. Instead, our approach is to study bilingual children as a window to understanding the development of semantic networks, as their experience disentangles exposure to concepts from exposure to their labels. While the Concepts Account and Labels Account are not necessarily mutually exclusive, strong versions of them make divergent predictions with respect to bilingual children's semantic development (see Figure 1 for an overview and schematic diagram). 
SEMANTIC PRIMING IN BILINGUAL CHILDREN

\section{Predictions from the Concepts versus Labels Accounts}

First, these two accounts differ in whether monolingual and bilingual children will start showing semantic priming from the same age. Under the Concepts Account, monolinguals and bilinguals should show a similar timing of semantic development, as presumably both groups encounter particular concepts (e.g., dogs and cats) with similar frequency. This leads to the key links between concepts in the semantic network to be strengthened equally in both language groups. However, under the Labels Account, the key links are between labels rather than between concepts. This would lead bilinguals to develop semantic networks at a slower rate than monolinguals, as they hear particular labels less often than monolinguals (e.g., a $d o g$ is sometimes labeled as “dog” and sometimes “chien”; Gollan, Montoya, Fennema-Notestine, \& Morris, 2005). Thus, the Labels Account predicts that bilinguals will show semantic priming from a later age than monolinguals.

Second, these accounts differ in their predictions for whether priming effects will be similar across bilingual children's two languages. Bilinguals' proficiency in the two languages is rarely perfectly balanced. Instead, they usually have a dominant language, which is typically the language that is heard and used most often (Pearson et al., 1997; Place \& Hoff, 2011). The Concepts Account predicts no difference in priming within the dominant and the non-dominant language. That is because semantic links are built through experience with concepts, which are activated regardless of whether a dominant or non-dominant language label is heard. Under the Labels Account, bilingual infants hear and use the labels in their dominant language (e.g., "dog”) more often than the labels in their non-dominant language (e.g., "chien"). This would result in earlier and stronger links between labels in the dominant language compared to the nondominant language. Thus, the Labels Account predicts stronger priming in the dominant than in 


\section{SEMANTIC PRIMING IN BILINGUAL CHILDREN}

the non-dominant language.

Finally, these two accounts differ in their predictions regarding within- and acrosslanguage priming. Within-language priming is tested by presenting the prime and target in the same language (e.g. English-English: “cat” - “dog”), while across-language priming is tested by presenting the prime and target in different languages (e.g. French-English: “cat" - "chien”). Under the Concepts Account, within-language and across-language priming will emerge at the same age, as in both cases priming is driven by connections between the concepts rather than the words that label them. This would be largely consistent with studies of bilingual adults, which have reported both within-language and across-language priming (Chen, 1990; Chen \& Ng, 1989; Tzelgov \& Eben-Ezra, 1992). However, under the Labels Account, within-language priming should develop earlier than across-language priming. This is because words in the same language tend to co-occur more often than words across two languages, except in occasional cases of language mixing (Bail, Morini \& Newman, 2015; Byers-Heinlein, 2013).

Only one published experiment to date has investigated the development of semantic networks in bilingual children. Singh (2013) used a priming task to test 2.5-year-old MandarinEnglish bilingual toddlers both within and across their two languages. Children heard a prime sentence followed by a target word that was either semantically related (e.g., "I saw a shoe! Sock!") or unrelated (e.g., "I saw a tree! Cup!”) to the prime. Primes and targets were presented in both of the children's languages, such that sometimes they were in the same language and other times they were in different languages. The results indicated a strong effect of language dominance. Specifically, children recognized the target word only when the prime word was in their dominant language, regardless of whether the target was in the same language as the prime or in the other language. However, children did not recognize the target word when the prime 


\section{SEMANTIC PRIMING IN BILINGUAL CHILDREN}

was in their non-dominant language. These results suggest that 2.5 -year-olds have semantic links both within and across their languages. However, language dominance appeared to have an effect, perhaps due to more robust lexical representations in their dominant than in their nondominant language, or else stronger semantic connections that spread from dominant-language words. The important role of language dominance provides somewhat stronger support for the Labels Account than for the Concepts Account. However, as this study did not test English nor Mandarin monolinguals, it cannot directly address developmental differences between monolinguals and bilinguals. Further, given that English monolinguals show priming effects as young as 21-24 months (Arias-Trejo \& Plunkett 2009; 2013), it is unclear whether bilinguals would show priming from the same age.

\section{Current studies}

The current paper reports a series of priming studies with monolingual and bilingual children. Study 1 served as a cross-language replication of within-language semantic priming in monolingual Canadian English-learning and monolingual Quebec French-learning 24-montholds. Study 2 used the same paradigm to test within-language semantic priming in FrenchEnglish bilingual 24-month-olds, investigating whether bilinguals would show within-language priming from the same age as monolinguals, and whether priming would be affected by language dominance. Finally, given results from Study 2 that did not find clear evidence for semantic priming in bilinguals of this age, Study 3 tested older 30-month-old French-English bilinguals. In contrast to Study 2, Study 3 tested both within-language and across-language priming. This study allowed comparison between bilinguals' performance in semantic priming within and across their languages. The results can be directly compared to the findings of Singh (2013), who tested Mandarin-English bilinguals of the same age, to examine whether semantic priming in bilinguals 
SEMANTIC PRIMING IN BILINGUAL CHILDREN

is affected by the particular language pair being learned. Together, these studies accorded several tests of the Concepts versus Labels Accounts.

\section{Study 1: Within-language semantic priming in 24-months-old monolinguals}

\section{Methods}

Participants. Forty 24-month-old full-term, healthy monolingual toddlers were included in the final sample. Half the children were learning English and half were learning French. Children were growing up in Montréal, a city where both English and French are widely spoken, and came primarily from middle class families. Children were primarily recruited via government birth lists. English monolinguals had an average age of $24 \mathrm{~m} 10 \mathrm{~d}$ (range: $23 \mathrm{~m} 8 \mathrm{~d}-$ $25 \mathrm{~m} 5 \mathrm{~d})$. There were 9 boys and 11 girls. French monolinguals had an average age of $24 \mathrm{~m} 15 \mathrm{~d}$ (range: $23 \mathrm{~m} 13 \mathrm{~d}-25 \mathrm{~m} 25 \mathrm{~d}$ ). There were 14 boys and 6 girls. Children's language background was assessed using the Language Exposure Questionnaire, a parental interview that asks detailed questions about a child's daily interactions in different languages (Bosch \& Sebastián-Gallés, 2001). They were exposed to their respective language at least $90 \%$ of the time. Children's productive vocabulary size was measured with either the English form of the MacArthur-Bates Communicative Development inventories (CDI; Fenson et al., 2007) or the Quebec French adaptation of the CDI (Boudreault, Cabirol, Trudeau, Poulin-Dubois, \& Sutton, 2007). The vocabulary size for each language group is reported in Appendix A (data for one French monolingual were missing). Unexpectedly, English monolinguals’ vocabulary size was significantly larger than French monolinguals' vocabulary size, $t(37)=2.75, p=.009, d=.90$.

A further 11 English monolinguals and 6 French monolinguals were tested but not included in the final sample because of technical issues (5 English, 1 French), experimenter error 


\section{SEMANTIC PRIMING IN BILINGUAL CHILDREN}

(3 English, 2 French), fussiness (1 English, 2 French), parental interference (1 English, 1 French), and reported ear infection (1 English).

Materials. Materials and methods were similar to Styles and Plunkett (2009). Two stimulus sets were created that were translations of each other, one English set and one French set. Twelve English words and their French translation were chosen as targets. Each target was paired with one related prime and one unrelated prime. Prime-target pairs were counterbalanced such that in some orders the target appeared following a related prime and in others it followed an unrelated prime (see Appendix B for full details of the study materials). All words were chosen to be highly imageable and likely to be understood by 2-year-olds. According to vocabulary norms, the English stimulus words were understood by a minimum of $50 \%$ of 18 months-olds according the American English CDI (Fenson et al., 2007). Because 18-month-old norms were not available for French learners, we ensured that all French words were understood by a minimum 50\% of 16-month-olds according to the Quebec French CDI norms (Boudreault, Cabirol, Trudeau, Poulin-Dubois, \& Sutton, 2007). Prime-target pairs were chosen that were both associatively and semantically related in order to increase the chance of revealing a priming effect in participants so young (Styles \& Plunkett, 2009; 2011). Related pairs had an attested forward relation in the Birkbeck Word Association Norms (Moss \& Older, 1996) or the South Florida Free Association Norms (Nelson, McEvoy, \& Schreiber, 2004). Unrelated pairs had no attested relation. No word pairs shared phonological onset, nor did any word-pairs rhyme. Visual stimuli consisted of 24 pictures of real objects. Twelve of the pictures were of the target objects, and twelve were of distracter objects. Distracters were chosen which had no attested relation to the target according to word association norms. Images were assigned to presentation pairs, such that items that might be especially attractive to children of two years of age (such as animate 


\section{SEMANTIC PRIMING IN BILINGUAL CHILDREN}

objects and body parts), and did not overlap on onset or rhyme, and were counterbalanced across distracter and target categories. All image pairs were presented on a $10 \%$ grey background.

French and English versions of the auditory stimuli were recorded from the same simultaneous bilingual female who spoke in a child-directed manner with no perceptible accent in either language. Prime words were recorded in a neutral sentence frame, either "I have a...", "I want a...", or "I saw a...", or their French translations. Target words were recorded in isolation.

Auditory and visual stimuli were combined into videos. See Figure 2 for a schematic diagram of a sample trial. First, a blank screen was presented, and a prime sentence was played, for example, "I want a truck!" where "truck" is the prime word. This was followed by a short prime-to-target inter-stimulus interval (ISI) of $200 \mathrm{~ms}$. Next, the target word (e.g. “Car!”) was played in isolation, and the visual stimulus pair appeared on screen at a stimulus onset asynchrony (SOA) of 400ms following Styles \& Plunkett (2011). The child was given $2500 \mathrm{~ms}$ of free-looking time with the image pair in each trial. The total duration of each trial was $5.3 \mathrm{~s}$.

Apparatus. A Tobii T60XL eye tracker system monitored and recorded each child's eye gaze during the study. The experimenter controlled the experiment from a PC in an adjacent room using Tobii Studio software and could see within the experimental room via the eye tracker's built-in camera. The child was positioned approximately $60 \mathrm{~cm}$ away from the 24 -inch monitor in a soundproof room. The sound was set at an average of $70 \mathrm{~dB}$.

Procedure. The parent(s) and child were greeted and brought to a playroom where the experimenter explained the study and had parents complete the consent form. Questionnaires were also administered in this room, before and after the main part of the study. During the study, the parent and child were shown to an adjacent soundproof experiment room. The child 


\section{SEMANTIC PRIMING IN BILINGUAL CHILDREN}

was seated on his or her parent's lap and faced the eye tracker. Parents listened to masking music over headphones, wore darkened sunglasses, and were instructed not to point or talk during the study. The eye tracker was calibrated to the child's eyes using a built-in five-point infant calibration routine. Once calibration was complete, the child's attention was brought to the centre of the screen with an attention getter, a round shape that pulsated and changed colour. When the child's gaze rested on the screen, as seen from the web camera, the experimenter pressed a key to begin the first trial of the study. The attention getter was repeated between each trial to ensure that the child's gaze was focused on the screen when the trial began.

Each test order included 12 trials: in half of the trials the prime word was related to the target, and in half of the trials it was unrelated. No auditory or visual stimulus was presented more than once in each test. Stimulus presentation was counterbalanced across eight test orders (the four versions in French being translations of the four English versions), such that each prime word was paired with both related and unrelated targets half of the time across participants, and the targets appeared on the right and left hand-side of the screen half the time within participants. Children were randomly assigned to a test order. Data were collected between December 2012 and February 2015, except for one infant who contributed data in March 2017 to complete the sample.

Results. Children's looking was measured within areas of interest around each target and distractor picture, using a rectangle approximately $2 \mathrm{~cm}$ larger than the visual stimuli on all sides. Data for each trial were collapsed across a time window that began $200 \mathrm{~ms}$ after the presentation of the picture pair (accounting for the time needed to process the auditory stimulus and shift eye gaze; Fernald, Pinto, Weinberg, \& McRoberts, 1998; Fernald, Swingley, \& Pinto 2001), and ended when the pictures disappeared from the screen, such that the size of the 


\section{SEMANTIC PRIMING IN BILINGUAL CHILDREN}

window of analysis was $2300 \mathrm{~ms}$. A proportion of target looking score was calculated for each child on each trial by dividing the total time the child spent looking at the target by the total time the child spent looking at either the target or the distractor. Trials where the child looked for less than $750 \mathrm{~ms}$ overall at either picture were excluded from the analysis. Out of six trials of each type, toddlers completed an average of 5.6 related (range: 3-6) and 5.6 unrelated (range: 4-6) trials on average, suggesting that overall, toddlers paid close attention during the study. A preliminary analysis found no effects of gender, so this factor was not included in the main analyses. Figure 3 shows an illustration of results by monolingual group (English, French). A 2 (relatedness: related, unrelated) x 2 (language: English, French) mixed ANOVA showed no significant effect of language, thus data were collapsed across the two monolingual groups. Monolinguals looked significantly longer on the related than the unrelated trials, $\mathrm{t}(39)=2.04, p$ $=.048, d=.32$, replicating previously-reported priming effects amongst monolingual children of this age. Follow-up two-tailed t-tests were performed to investigate whether children in each monolingual group looked at the target above chance (.5) on each trial type, and results are presented in Table 1. Both English-learners and French-learners showed above-chance looking to the target on the related prime trials, but were not reliably different from chance on the unrelated prime trials.

Finally, we examined whether children's vocabulary size was related to the priming effect. For each child, we calculated a priming difference score as the proportion looking to the target on related trials minus the proportion looking to the target on unrelated trials. This was not related to children's productive vocabulary size, $r(38)=-.098, p=.55$.

\section{Discussion}


SEMANTIC PRIMING IN BILINGUAL CHILDREN

Overall, Study 1 replicated previous findings that monolingual learners show semantic priming at age 24 months, extending results reported form British English learning toddlers (Arias-Trejo \& Plunkett 2009; 2013; Styles \& Plunkett, 2009) to toddlers learning Canadian English and Quebec French. We do note that a few aspects of our design differed from some studies on semantic priming in young children. We used an SOA of 400ms, while it is more common to use an SOA of $200 \mathrm{~ms}$. However, studies that have compared this directly have not found a difference between these conditions (Styles \& Plunkett, 2009), or have reported stronger priming at 400ms (Styles, Arias-Trejo, \& Plunkett, 2008). Also, while we only tested conditions with related and unrelated primes, some studies have included an additional condition where the target is not named after the prime word. This is typically used to rule out visual mediation explanations, whereby the priming could potentially increase interest to a related visual target even in the absence of its label. However, most studies have not reported increased looking to the target in these cases (e.g., Arias-Trejo \& Plunkett, 2009; 2013). Although we did not directly test this condition in our study, these previous results argue against visual mediation explanations in this paradigm. Overall, Study 1 provided a general validation of our paradigm and procedure, motivating the testing of same-aged bilinguals in Study 2.

\section{Study 2: Within-language semantic priming in 24-months-old bilinguals}

To further understand the role of experience in the development of semantic priming, Study 2 tested bilingual French-English 24-month-olds. We used the same procedure as Study 1 but tested children using both French and English stimuli. This allowed us to investigate whether priming would vary as a function of whether the prime-target pairs were in toddlers' dominant versus non-dominant language. Under the Concepts Account, we should observe a similar priming effect in Study 2 participants (24-month-old bilinguals) as in Study 1 participants (24- 
SEMANTIC PRIMING IN BILINGUAL CHILDREN

month-old monolinguals). Further, bilinguals' performance should be similar in their dominant and their non-dominant language. In contrast, under the Labels Account, Study 2 participants (24-month-old bilinguals) should show a weaker or absent overall priming effect compared to the monolingual Study 1 participants (24-month-old monolinguals). Further, any observed priming should be stronger in their dominant language compared to their non-dominant language.

\section{Methods}

Participants. Sixteen full-term, healthy French-English bilingual children aged 24 months $(M=24 \mathrm{~m} 13 \mathrm{~d}$, range $=23 \mathrm{~m} 16 \mathrm{~d}-25 \mathrm{~m} 5 \mathrm{~d})$ were included in the final sample. Ten were male and 6 were female. As in Study 1, children's language background was assessed using the Language Exposure Questionnaire (Bosch \& Sebastián-Gallés, 2001). Fifteen children were regularly exposed to both English and French from birth, and 1 was exposed to French from birth and English from age 2 months. They all had an overall exposure to each language ranging from $25 \%-75 \%$. Children did not have any systematic exposure to a third language. A further nine bilinguals were tested but not included in the final sample because of technical issues (5), fussiness (3), and experimenter error (1).

Children's vocabulary size was quantified in both languages using American English (Fenson et al., 2007) and Quebec French adaptation of the CDI (Boudreault, Cabirol, Trudeau, Poulin-Dubois, \& Sutton, 2007). A parent who was familiar with a child's vocabulary in a particular language completed the form, such that in some cases the same parent filled out both forms and in other cases different parents filled out each form. Vocabulary data were missing for one toddler. 


\section{SEMANTIC PRIMING IN BILINGUAL CHILDREN}

Languages were categorized as dominant or non-dominant based on reported vocabulary size. The language with the largest vocabulary size was considered the dominant language. For the child with incomplete vocabulary data, the language heard most often was considered the dominant language. Nine bilinguals were English-dominant and seven bilinguals were Frenchdominant. Measures of bilinguals' vocabulary size are presented in Appendix A. Total vocabulary size was calculated by summing vocabulary in both languages. Bilinguals' total vocabulary size was between that of the English and French monolingual groups, and was not statistically different from either group, $p>.10$. Translation equivalents were calculated as the number of words lexicalized in both languages (i.e., across-language synonyms like $d o g$ and chien). Total conceptual vocabulary size was calculated by subtracting translation equivalents from toddlers' total vocabulary size, to provide an estimate of the total number of concepts lexicalized by each child. Bilinguals' average total conceptual vocabulary was significantly smaller than the English monolinguals' vocabulary size $t(33)=3.80, p<.001$, but not significantly different from the French monolinguals' vocabulary size, $t(32)=1.41, p=.17$. Thus, while bilinguals knew fewer words than monolinguals in each language, they knew a comparable number of words overall, at least in relation to the French monolinguals - the group that showed semantic priming in Study 1.

Materials, apparatus, and procedure. The materials and apparatus for Study 2 were identical to those used in Study 1. The procedure was also similar, except bilingual children were tested in both their dominant and their non-dominant language. Trials in the two languages were completed in two blocks that were identical to those presented to monolinguals, with a short break in between. The order in which the two blocks were presented was randomly assigned such that half of toddlers (8) were tested in their dominant language first, and half $(8)$ were tested in 


\section{SEMANTIC PRIMING IN BILINGUAL CHILDREN}

their non-dominant language first. For each block, children were randomly assigned to one of the test orders used in Study 1, with the condition that the two blocks had opposing relations between cue words and targets to avoid any learned associations (i.e. words that had previously been presented with a related prime were presented with an unrelated prime, and vice versa). In sum, every child was tested on four trial types: dominant language trials with either related or unrelated primes, and non-dominant language trials with either related or unrelated primes. Data were collected between August 2015 and January 2017.

Results. Data were collapsed by area of interest, within the same time window as in Study 1. Trials where the child looked for less than $750 \mathrm{~ms}$ overall at both the target and distractor were excluded from the analysis. Each child completed a minimum of two trials of each type. On average in each of the four trial types, children completed an average of $5.5-5.9$ trials out of a possible six. This suggested that overall, they were highly attentive during the study.

To test the main hypotheses, children's proportion looking time to the correct object was analyzed in a 2 (relatedness: related, unrelated) x 2 (dominance: dominant, non-dominant) ANOVA. There were no significant main effects of relatedness, $F(1,15)=2.02, p=.18, \eta^{2}=$ .021 , indicating that bilinguals did not show different performance as a function of whether the prime was related or unrelated. There was also no significant main effect of dominance, $F(1,15)$ $=.22, p=.64, \eta^{2}=.0036$. Finally, there was no significant interaction between relatedness and dominance, $F(1,15)=.025, p=.88, \eta^{2}<.001$. Paired-samples t-tests found no significant difference in looking to the target on the related prime compared to the unrelated prime trials in toddlers' dominant language $t(15)=.96, p=.18, d_{z}=.24$, nor in their non-dominant language $t(15)=1.03, p=.16, d_{z}=.26$. Results for the dominant and non-dominant language are 


\section{SEMANTIC PRIMING IN BILINGUAL CHILDREN}

illustrated in Figure 3. Follow-up two-tailed t-tests were performed to investigate whether children looked at the target above chance (.5) on each trial type, and results are presented in Table 1. Looking was significantly above chance on all trial types $(p s<.05)$, except unrelated trials with a dominant-language prime $(p=.11)$.

To directly compare bilinguals' performance to monolinguals' performance in Study 1, we collapsed across dominant and non-dominant language trials for bilinguals, and performed a 2 (relatedness: related, unrelated) x 2 (language group: monolingual, bilingual) ANOVA. Here, there was a significant effect of relatedness, $F(1,54)=5.96, p=.018, \eta^{2}=.034$, with no evidence of an interaction between relatedness and language group, $F(1,54)=.047, p=.82, \eta^{2}<.001$. The main effect of language group was also not significant $F(1,54)=1.40, p=.24, \eta^{2}=.017$. We will discuss how to reconcile these results with those in which each group was analyzed separately in the discussion.

To examine individual differences, we proceeded as in Study 1. We calculated a prime score as the difference in proportion target looking between related and unrelated primes. Then, we examined correlations between prime scores on each trial type (dominant and non-dominant) and vocabulary size in that language. For dominant-language trials, there were positive but nonsignificant relations between prime score and vocabulary size $(r(14)=.20, p=.46)$. The opposite pattern was observed for non-dominant-language trials: children with smaller non-dominant language vocabulary sizes showed significantly stronger priming $(r(14)=-.52, p=.039)$. This suggested that children whose language knowledge was less balanced - those with more vocabulary knowledge in the dominant language and less vocabulary knowledge in the nondominant language - might show stronger priming. To test this possibility directly, we calculated the proportion of vocabulary items that were produced in the dominant and non-dominant 
SEMANTIC PRIMING IN BILINGUAL CHILDREN

languages as a direct index of how balanced children's vocabulary knowledge was. However, vocabulary balance was not significantly correlated with priming in either the dominant $(r(14)=$ $.20, p=.46)$, nor the non-dominant language $r(14)=-.07, p=.80)$.

\section{Discussion}

To understand the role of bilingual experience on the development of semantic priming, we tested 24-month-old French-English bilinguals using the same stimuli as Study 1. Toddlers were tested in both of their languages, and we compared priming in bilinguals' dominant and non-dominant languages. Our study did not find evidence for semantic priming in bilinguals of this age. They recognized the targets similarly on both related and on unrelated trials. Further, there was no difference in performance across their dominant and non-dominant languages. However, it should be noted that our observed effect size for related versus unrelated prime trials was $d_{z}=.24$ for the dominant language and $d_{z}=.26$ for the non-dominant language, which is only somewhat smaller than the effect observed in Study $1\left(d_{z}=.32\right)$. Moreover, when the data were pooled, there was a significant overall priming effect in toddlers as a whole, and no significant interaction with language background (monolingual vs. bilingual). Thus, while we

found reliable evidence of priming in the monolingual group and not in the bilingual group, it is not clear from these results whether monolinguals and bilinguals follow a different developmental trajectory. Therefore, it is difficult to draw strong conclusions about the predictions of the Concepts versus Labels Accounts. Nonetheless, our results do suggest that semantic priming effects in this paradigm at this age are not necessarily robust across all groups of learners.

Given the lack of statistically reliable evidence for semantic priming for 24-month-old bilinguals in Study 2, Study 3 tested an older group of French-English bilingual children: 30- 
SEMANTIC PRIMING IN BILINGUAL CHILDREN

month-olds. We expected that semantic development would be more advanced at this age, and that bilinguals would show semantic priming. While Study 2 tested only within-language semantic priming, Study 3 tested both within-language and across-language semantic priming. This provided several further opportunities to test predictions made by the Concepts Account and the Labels Account.

\section{Study 3: Within- and across- language semantic priming in 30-month-old bilinguals}

Study 2 found no evidence of within-language semantic priming in 24-month-old bilinguals in either their dominant or their non-dominant language. To further investigate the developmental trajectory of semantic priming in bilinguals, Study 3 tested 30-month-old FrenchEnglish bilinguals. In addition to testing children in within-language semantic priming (prime and target in the same language) as in Study 2, we also tested children in across-language priming (prime and target in different languages). The Concepts Account predicts that priming will be similar regardless of the languages of the prime and the target words. However, the Labels Account predicts stronger priming in the dominant compared to the non-dominant language. Further, it also predicts stronger priming when prime and target are in the same language (within-language priming), as compared to when they are in different languages (across-language priming).

\section{Methods}

Participants. Sixteen full-term, healthy 30-months-old French-English bilingual toddlers $(M=30 \mathrm{~m} 25 \mathrm{~d}$, range: $29 \mathrm{~m} 21 \mathrm{~d}-31 \mathrm{~m} 6 \mathrm{~d})$ were included in the final sample. Nine were male, and seven were female, and none had participated in Study 2. Children's language background, dominance, and vocabulary size were assessed as in Study 2. All children were simultaneous bilinguals who had been exposed to both languages since birth, with exposure to each language 


\section{SEMANTIC PRIMING IN BILINGUAL CHILDREN}

ranging from $25 \%-75 \%$. They did not have any systematic exposure to a third language. Nine bilinguals were English-dominant and seven bilinguals were French-dominant. Vocabulary measures are reported in Table 1 . An additional 15 children were tested but not included in the final sample because of low birth-weight (3), reported health issues (3), technical issues (3), fussiness (2), and parental interference (1). Finally, we excluded children who did not contribute to the data for a minimum of 1 trial per condition (2).

Materials, apparatus and procedure. The materials and apparatus for Study 3 were based on those used in Study 2, but presented a few differences. A few changes were made to ensure that primes, targets, and distractors did not share phonological onset or rhyme in either of the two languages (see Appendix C for full details of the study materials). Cognate words (e.g. English “banana”, French "banana”) were avoided for primes and targets, but permitted for distractors. Children were tested in two twelve-trial blocks that were consistent in the language of the carrier phrase (dominant-language or non-dominant language), for a total of 24 test trials. Whereas in Study 2 the target and prime were always in the same language, in the current study, on half the trials the prime and the target word were in the same language (within-language trials), and on half the trials the prime and the target word were in different languages (acrosslanguage trials). Further, in half the trials the prime word was related to the target, and in half the trials the prime word was unrelated to the target. This resulted in each child being tested in 8 different trial types that fully crossed the language of the prime (dominant, non-dominant), the language of the target relative to the prime (within-language, across-language), and the relatedness of the pair (related, unrelated). Children saw trials presented in one of 8 randomlyassigned study orders that counterbalanced the language of the first block (dominant or non- 


\section{SEMANTIC PRIMING IN BILINGUAL CHILDREN}

dominant language), whether a particular prime was paired with a related or unrelated target, and whether a particular target appeared on the right or left hand-side of the screen.

Results. Data were collapsed by area of interest, within the same time window as in Studies 1 and 2. Trials where the child looked for less than $750 \mathrm{~ms}$ overall at both the target and distractor were excluded from the analysis. Each child completed a minimum of 1 trial of each type, with an average of 2.5-2.8 trials out of a possible 3 across the different trial types. This suggested that overall, children were highly attentive during the study.

Results by group and trial type are illustrated in Figure 4. Proportion looking to target was analyzed with a 2 (prime dominance: dominant vs. non-dominant language) x 2 (target language relative to the prime: within-language vs. across-language) x 2 (relatedness: related vs. unrelated) within-subjects ANOVA. There was only one statistically significant effect, which was the main effect of relatedness, $F(1,15)=94.8, p<.001, \eta^{2}=.078$. This indicated that 30 month-old bilinguals looked more at the target on trials with related primes than on trials with unrelated primes. There was no significant main effect of prime dominance, $F(1,15)=1.53, p=$ $.23, \eta^{2}=.0086$, nor of target relative to prime, $F(1,15)=.23, p=.63, \eta^{2}<.001$. Further, no two-way interaction was found between prime dominance and target language relative to the prime, $F(1,15)=.035, p=.85, \eta^{2}<.001$, relatedness and prime dominance, $F(1,15)=.035, p$ $=.85 ., \eta^{2}<.001$, or relatedness and target language relative to the prime, $F(1,15)=.45, p=$ $.51 ., \eta^{2}=.0030$ Finally, the three-way interaction was not statistically significant, $F(1,15)=$ $.05, p=.82, \eta^{2}<.001$.

To follow-up, we conducted single-sample t-tests to determine the trial types where children showed above-chance recognition of the target word (chance $=.5$ ). Means, $t$ - and $p$ values are presented in Table 1 . In most, but not all cases, looking to the target was significantly 
SEMANTIC PRIMING IN BILINGUAL CHILDREN

or marginally above chance for trials were the prime was related ( $p$ 's $<.05$ ), and looking was never different from chance on trials where the prime was unrelated. We note that, as compared to Studies 1 and 2, this design presents fewer trials of each type (3 vs. 6), which would decrease the statistical power to detect a significant difference from chance. Nevertheless, the overall pattern is consistent with the main effect of relatedness in the omnibus ANOVA.

Finally, we examined individual differences by correlating the priming difference score with vocabulary size in the dominant and non-dominant languages separately for each condition. This yielded 8 correlation coefficients, none of which were statistically significant even prior to correction for multiple comparisons.

\section{Discussion}

The results from Study 3 clearly demonstrate that, by age 30-months, bilingual children show semantic priming. Bilinguals looked successfully at the targets preceded by related primes, but not at those preceded by unrelated primes. This provides clear evidence that bilingual toddlers have developed a semantic network by this age. We do note some differences between the procedure used in Studies 2 and 3. In particular, Study 3 intermixed within-language and across-language priming trials. However, if anything this would have likely made Study 3 more difficult than Study 2, and thus cannot account for why 24-month-old bilinguals in Study 2 did not show a priming effect even in this easier task. Moreover, because both types of priming were tested, this approach precluded us from testing monolingual children in the Study 3 paradigm.

We did not fully replicate the findings of Singh (2013). Unlike the Mandarin-English bilinguals of the same age in that study, French-English bilinguals' performance did not depend on the language of the prime (dominant or non-dominant), or whether they were presented in the 


\section{SEMANTIC PRIMING IN BILINGUAL CHILDREN}

same or different languages. These divergent results in two different populations of bilinguals (French-English and Mandarin-English) suggest that semantic development in bilinguals could be affected by the language pair being learned (see also Floccia et al., 2016). Our results demonstrate that 30-month-old French-English bilinguals show strong semantic links in their dominant and in their non-dominant language, both within and across their languages. However, we also note that it is possible that a language dominance effect does exist even in FrenchEnglish bilinguals of this age, but it is perhaps too weak to be consistently detected in this paradigm.

\section{General Discussion}

The goal of this research was to understand what types of experience underlie the development of children's semantic networks. We tested two competing hypotheses: the Concepts Account and the Labels Account. Under the Concepts Account, children's early semantic networks are built through encountering related or co-occurring concepts. Here, when a child encounters a dog, the concept of $d o g$ is activated, which in turn activates the related concept of cat. This pattern of co-activation would make no distinction with regards to the particular words that are used to refer to the dog and cat. Under the Labels Account, it is experience with particular labels that form the associations of the semantic network. Here, it is the frequent co-occurrence of the related labels "cat" and "dog" that strengthens the links of the semantic network. While these two theories are difficult to tease apart in the case of monolingual children, whose experience with concepts and labels is tightly coupled, their predictions differ in the case of bilingual children because they are exposed to two labels for each concept they encounter. This unique aspect of bilingualism allowed us to test the three competing predictions that these accounts make. 


\section{SEMANTIC PRIMING IN BILINGUAL CHILDREN}

Our first approach was to compare semantic priming in three groups of 24-month-old toddlers: monolingual Canadian English and Quebec French learners (Study 1), and bilingual English-French learners (Study 2). As mentioned, bilinguals hear one of two possible labels (one from each language) each time they encounter a particular concept, reducing the frequency with which they hear any particular label. For example, while bilingual children likely see just as many dogs as monolinguals, sometimes it is labeled "dog" and at other times "chien." This divided exposure to each label could result in weaker links between labels, which could lead to a delay in the emergence of semantic associations (Gollan et al., 2005). Thus, the Labels Account predicts bilinguals will show signs of developing a semantic network at a later age compared to monolinguals, while the Concepts Account predicts that monolinguals and bilinguals will develop on the same schedule. We initially tested toddlers at age 24-months, which was chosen because a number of studies with British English-learning toddlers have found evidence for semantic priming at this age (Arias-Trejo \& Plunkett, 2009; Styles \& Plunkett, 2009; 2013).

Overall, our results from 24-month-olds were somewhat equivocal. In all groups, we found directional effects where toddlers looked more at the target object when its label was preceded by a related than by an unrelated prime. However, while the observed priming effect was statistically significant for monolinguals at 24 months, it was not for bilinguals. Bilinguals only showed a statistically significant priming effect at a later age of 30-month-old. Later emergence of priming in bilinguals than monolinguals would lend support to the Labels Account. However, 24-month-old monolinguals and bilinguals did not differ from each other statistically, and the two groups' effect sizes were in a comparable range $\left(d_{z}=.32\right.$ for monolinguals; $d_{z}=.24$ for bilinguals' dominant language). Thus, although our results suggest an evolution in terms of semantic priming in bilinguals between the ages of 24 and 30 months, our evidence was not 


\section{SEMANTIC PRIMING IN BILINGUAL CHILDREN}

conclusive with respect to whether bilingual-learning infants develop semantic networks at a different age from monolingual-learning infants. Instead, these results indicate that at age 24months, priming effects may be somewhat small and difficult to observe in this paradigm.

Our second approach was to investigate the role of language dominance in bilingual semantic priming. Under the Labels Account, associations between related words in a bilingual's dominant language should be stronger and earlier-acquired than those in the non-dominant language. However, both the dominant and the non-dominant languages should show similar associations under the Concepts account. Thus, we looked for an effect of language dominance on priming in 24-month-old bilinguals (Study 2) and 30-month-old bilinguals (Study 3). At age 24 months, bilinguals did not show priming in either their dominant nor their non-dominant languages, while at 30 months they showed priming in both languages. The lack of a language dominance effect supports the Concepts Account.

Our third approach was to compare bilinguals' semantic priming within and across their languages (Study 3). Under the Labels Account, associations between words in the same language will be stronger than associations between words across the two languages. This would result in bilinguals showing within-language semantic priming (prime and target word in the same language) before across-language semantic priming (prime and target in different languages). However, under the Concepts Account, we should observe similar effects for withinand across-language priming, as these effects would be mediated via experience with concepts, which are not language-specific. Our results confirmed both within-language and acrosslanguage priming at age 30-months, which occurred whether the prime was in the dominant or the non-dominant language (Study 3). This pattern of results supports the Concepts Account. However, it should be noted that these results differ from Singh (2013), who observed a priming 


\section{SEMANTIC PRIMING IN BILINGUAL CHILDREN}

effect with 30-months-old Mandarin-English bilinguals only when the prime was presented in the dominant language. This could indicate that the particular language pair learned plays a role in the development of semantic networks. Ongoing research with a variety of bilingual populations will provide much-needed data to understand potential differences (e.g., Floccia et al., 2016; Rämä \& Sirri, 2017; Wojcik \& Werker, 2017).

Overall, the balance of evidence from this series of studies provides stronger evidence for the Concepts account than the Labels account. Under the Labels account, we predicted 1) developmental differences between monolinguals and bilinguals, 2) an effect of language dominance in bilinguals' priming, and 3) stronger priming within bilinguals' language compared to across bilinguals' languages. Together, the absence of these effects support the Concepts account, which predicted no differences on these dimensions.

However, while we have framed this paper in terms of a strict dichotomy between the Labels and the Concepts accounts, it is also probable that children's encounters with concepts and labels both contribute to their semantic development to some degree. This view is consistent with that put forward by Bilson et al. (2015) who proposed that bilingual children might learn about concepts at the same rate as monolinguals, but it takes them longer to learn to name the concept because of its inconsistent labeling (sometimes in one language and sometimes in the other). Moreover, there is some previous empirical support for the Labels account, for example stronger priming reported in the dominant than the non-dominant language (Singh, 2013; although we did not replicate this effect), and an observed correlation between priming in English and English vocabulary size (Wojcik \& Werker, 2017). These findings are somewhat difficult to reconcile with our results, which did not find any clear support for the Labels account. Future research will be needed to understand the relative contribution of labels and 


\section{SEMANTIC PRIMING IN BILINGUAL CHILDREN}

concepts in semantic development at different ages, and whether this is affected by factors that could explain seemingly discrepant findings in bilinguals such as the language pair being learned.

Converging evidence from other experimental approaches could provide an additional way to compare monolinguals and bilinguals. For example, brain-based measures such as eventrelated potentials have been revealing of semantic processing in monolinguals as young as 18 months (Rämä et al., 2013; Sirri \& Rämä, 2015), and studies using this method to investigate semantic priming in bilinguals are underway (Sirri \& Rämä, 2017). Other work in progress is using an auditory-only paradigm with bilingual infants (Wojcik \& Werker, 2017). Approaches that involve teaching children new words with different types of semantic relations could also be promising (e.g., Wojcik \& Saffran, 2013; 2015), allowing researchers to manipulate children's exposure to different concepts and labels in the lab in ways that mimic bilingualism.

Finally, our results have implications for understanding language acquisition in bilingual children. A question of ongoing interest is understanding how monolingual and bilingual children compare developmentally. Some research has indicated that bilinguals' divided input results in a protracted time course of development (e.g., bilinguals know fewer words in each of their languages than monolinguals know in their only language; Hoff et al., 2012). However, other work indicates that monolinguals and bilinguals develop at the same pace (e.g., monolinguals and bilinguals have similar total vocabulary sizes when both languages are taken into account; Core et al., 2013). Our results at 24-months cannot clearly say whether the initial establishment of links in the semantic network coalesce later for bilinguals than monolinguals, as we found that priming effects at this age were small and variable even amongst monolinguals. However, our results confirm that, by age 30 months, bilinguals have developed semantic 
SEMANTIC PRIMING IN BILINGUAL CHILDREN

networks that link related words and meanings both within and across their languages. Despite their more complex linguistic experience, bilingual children are able to encode the rich semantic relations that characterize their early environments. 
SEMANTIC PRIMING IN BILINGUAL CHILDREN

\section{References}

Arias-Trejo, N., \& Plunkett K. (2009). Lexical-semantic priming effects during infancy.

Philosophical Transactions of the Royal Society B: Biological Sciences, 364, 36333647. doi: $10.1098 /$ rstb.2009.0146

Arias-Trejo, N., \& Plunkett, K. (2013). What's in a link: Associative and taxonomic priming effects in the infant lexicon. Cognition, 128, 214-227. doi:

10.1016/j.cognition.2013.03.008

Bail, A., Morini, G., \& Rochelle. N., (2015). Look at the gato! Code-switching in speech to toddlers. Journal of Child Language, 42, 1071-1101. doi:

\section{$10.1017 / \mathrm{S} 0305000914000695$}

Beckage, N., Smith, L., \& Hills, T. (2011). Small worlds and semantic network growth in typical and late talkers. PloS one, 6, e19348. doi: 10.1371/journal.pone.0019348

Bosch, L., \& Sebastián-Gallés, N. (2001). Evidence of early language discrimination abilities in infants from bilingual environments. Infancy, 2, 29-49. doi: 10.1207/S15327078IN0201_3

Boudreault, M. C., Cabirol, É. A., Trudeau, N., Poulin-Dubois, D., \& Sutton, A. (2007). Les inventaires MacArthur du développement de la communication: Validité et données normatives préliminaires. Revue canadienne d'orthophonie et d'audiologie, 31, 27-37.

Bilson, S., Yoshida, H., Tran, C. D., Woods, E. A., \& Hills, T. T. (2015). Semantic facilitation in bilingual first language acquisition. Cognition, 140, 122-134. doi: 10.1016/j.cognition.2015.03.013

Byers-Heinlein, K. (2017). Bilingualism affects infants' expectations about how words refer to kinds. Developmental Science, 20, doi: 10.1111/desc.12486 
SEMANTIC PRIMING IN BILINGUAL CHILDREN

Byers-Heinlein, K. (2013). Parental language mixing: Its measurement and the relation of mixed input to young bilingual children's vocabulary size. Bilingualism: Language and Cognition, 16, 32-48. doi: 10.1017/S1366728912000120

Byers-Heinlein, K., Fennell, C.T., \& Werker, J.F. (2013). The development of associative word learning in monolingual and bilingual infants. Bilingualism: Language and Cognition, 16, 198-205. doi: 10.1017/S1366728912000417

Byers-Heinlein, K., \& Werker, J. F. (2009). Monolingual, bilingual, trilingual: Infants' language experience influences the development of a word-learning heuristic. Developmental Science, 12, 815-823. doi: 10.1111/j.1467-7687.2009.00902

Byers-Heinlein, K., \& Werker, J. F. (2013). Lexicon structure and the disambiguation of novel words: Evidence from bilingual infants. Cognition, 128, 407-416. doi:

10.1016/j.cognition.2013.05.010

Cancho, R. F., \& Solé, R. V. (2001). The small world of human language. Proceedings of the Royal Society of London B: Biological Sciences, 268, 2261-2265. doi:

$10.1098 / \mathrm{rspb} .2001 .1800$

Chen, H. C., \& Ng, M. L. (1989). Semantic facilitation and translation priming effects in Chinese-English bilinguals. Memory \& Cognition, 17, 454-462. doi: $10.3758 / \mathrm{BF} 03202618$

Chen, H. C. (1990). Lexical processing in a non-native language: Effects of language proficiency and learning strategy. Memory \& Cognition, 18, 279-288. doi: 10.3758/BF03213881

Collins, A. M., \& Loftus, E. F. (1975). A spreading-activation theory of semantic processing. Psychological review, 82, 407. doi:10.1037/0033-295X.82.6.407 


\section{SEMANTIC PRIMING IN BILINGUAL CHILDREN}

Core, C., Hoff, E., Rumiche, R., \& Señor, M. (2013). Total and conceptual vocabulary in Spanish-English bilinguals from 22 to 30 Months: Implications for assessment. Journal of Speech, Language and Hearing Research, 56, 1637-1649. doi: 10.1044/1092$4388(2013 / 11-0044)$

DeAnda, S., Poulin-Dubois, D., Zesiger, P., \& Friend, M. (2016). Lexical processing and organization in bilingual first language acquisition: Guiding future research. Psychological Bulletin, 142, 655-667. doi: 10.1037/bul0000042

Fenson, L., Marchman, V. A., Thal, D. J., Dale, P. S., Reznick, J. S., and Bates, E. (2007). MacArthur-Bates Communicative Development Inventories: User's Guide and Technical Manual - Second Edition. Baltimore: Brookes Publishing.

Fernald, A., Pinto, J. P., Swingley, D., Weinbergy, A., \& McRoberts, G. W. (1998). Rapid gains in speed of verbal processing by infants in the 2nd year. Psychological Science, 9, 228231. doi: $10.1111 / 1467-9280.00044$

Fernald, A., Swingley, D., \& Pinto, J. P. (2001). When half a word is enough: Infants can recognize spoken words using partial phonetic information. Child development, 72, 1003 1015. doi: 10.1111/1467-8624.00331.

Floccia, C., Kwok, R. W., Delle Luche, C., Chow, J., Horváth, K., Cattani, A., Goslin, J., White, L., \& Plunkett, K. (2016, May). Linguistic distance and semantic priming in 24- to 27month-old bilingual children. Poster presented at the International Conference on Infant Studies, New Orleans, LA.

Gollan, T. H., Montoya, R. I., Fennema-Notestine, C., \& Morris, S. K. (2005). Bilingualism affects picture naming but not picture classification. Memory \& Cognition, 33, 1-15. doi: $10.3758 / \mathrm{bf03193224}$ 
SEMANTIC PRIMING IN BILINGUAL CHILDREN

Hills, T. T., Maouene, M., Maouene, J., Sheya, A., \& Smith, L. (2009). Longitudinal analysis of early semantic networks: preferential attachment or preferential acquisition? Psychological science, 20, 729-739. doi: 10.1111/j.1467-9280.2009.02365.x

Hoff, E., Core, C., Place, S., Rumiche, R., Señor, M., \& Parra, M. (2012). Dual language exposure and early bilingual development. Journal of Child Language, 39, 1-27. doi: $10.1017 / \mathrm{S} 0305000910000759$

Houston-Price, C., Caloghiris, Z., \& Raviglione, E. (2010). Language experience shapes the development of the mutual exclusivity bias. Infancy, 15, 125-150. doi: 10.1111/j.15327078.2009.00009.x

Legacy, J., Reider, J., Crivello, C., Kuzyk, O., Friend, M., Zesiger, P., \& Poulin-Dubois, D. (2016). Dog or chien? Translation equivalents in the receptive and expressive vocabularies of young French-English bilinguals. Journal of Child Language, 44, 881904. doi: 10.1017/S0305000916000295

Legacy, J., Zesiger, P., Friend, M., \& Poulin-Dubois, D. (2015). Vocabulary size, translation equivalents, and efficiency in word recognition in very young bilinguals. Journal of Child Language, 43, 760-783. doi: 10.1017/S0305000915000252

Mani, N., \& Plunkett, K. (2010). In the infant's mind's ear: Evidence for implicit naming in 18-month-olds. Psychological Science, 21, 908-913. doi: 10.1177/0956797610373371

Mani, N., \& Plunkett, K. (2011). Phonological priming and cohort effects in toddlers. Cognition, 121, 196-206. doi: 10.1016/j.cognition.2011.06.013

Moss, H., \& Older, L. (1996). Birkbeck Word Association Norms. Psychology Press. 
SEMANTIC PRIMING IN BILINGUAL CHILDREN

Nelson, D. L., McEvoy, C. L., \& Schreiber, T. A. (2004). The University of South Florida free association, rhyme, and word fragment norms. Behavior Research Methods, Instruments, \& Computers, 36, 402-407. doi: 10.3758/bf03195588

Pearson, B. Z., Fernández, S. C., \& Oller, D. K. (1993). Lexical development in bilingual infants and toddlers: Comparison to monolingual norms. Language Learning, 43, 93120. doi: 10.1111/j.1467-1770.1993.tb00174.x

Pearson, B. Z., \& Fernández, S. C. (1994), Patterns of interaction in the lexical growth in two languages of bilingual infants and toddlers. Language Learning, 44, 617-653. doi: 10.1111/j.1467-1770.1994.tb00633.x

Pearson, B. Z., Fernández, S. C., Lewedeg, V., \& Oller, K. (1997). The relation of input factors to lexical learning by bilingual infants. Applied Psycholinguistics, 18, 41-58. doi: $10.1017 / \mathrm{S} 0142716400009863$

Place, S., \& Hoff, E. (2011). Properties of dual language exposure that influence 2-year-olds' bilingual proficiency. Child Development, 82, 1834-1849. doi: 10.1111/j.14678624.2011.01660.x

Rämä, P., \& Sirri, L. (2017, April). Do similar or distinct neural mechanisms underlie lexicalsemantic processing in both languages of the bilingual children? Paper presented at the Biennial Meeting of the Society for Research on Language Development, Austin, TX.

Rämä, P., Sirri, L., \& Serres, J. (2013). Development of lexical-semantic language system: N400 priming effect for spoken words in 18-and 24-month old children. Brain and Language, 125, 1-10. doi: 10.1016/j.bandl.2013.01.009

Singh, L. (2013). One world, two languages: Cross-language semantic priming in bilingual toddlers. Child Development, 85, 755-766. doi: 10.1111/cdev.12133 
SEMANTIC PRIMING IN BILINGUAL CHILDREN

Sirri, L., \& Rämä, P. (2015). Cognitive and neural mechanisms underlying semantic priming during language acquisition. Journal of Neurolinguistics, 35,1-12. doi:

10.1016/j.jneuroling.2015.01.003

Steyvers, M., \& Tenenbaum, J. B. (2005). The large-scale structure of semantic networks:

Statistical analyses and a model of semantic growth. Cognitive Science, 29, 41-78. doi: 10.1207/s15516709cog2901_3.

Styles, S. J., Arias-Trejo, N., \& Plunkett, K. (2008). Priming and lexical interference in infancy. Proceedings of the 30th Annual Conference of the Cognitive Science Society, 612-616.

Styles, S. J., \& Plunkett, K. (2009). How do infants build a semantic system? Language and Cognition, 1, 1-24. doi: 10.1515/LANGCOG.2009.001

Styles, S., \& Plunkett, K. (2011) Early links in the early lexicon: Semantically related word-pairs prime picture looking in the second year. In G. Gaskell \& P. Zwitzerlood (Eds.), Lexical Representation: A Multidisciplinary Approach (pp. 51-88). Berlin: Mouton de Gruyter.

Tzelgov, J., \& Eben-Ezra, S. (1992). Components of the between-language semantic priming effect. European Journal of Cognitive Psychology, 4, 253-272. doi: 1080/09541449208406187

Werker, J.F., \& Byers-Heinlein, K. (2008). Bilingualism in infancy: First steps in perception and comprehension. Trends in Cognitive Sciences, 12, 144-151. doi:

10.1016/j.tics.2008.01.008

Willits, J. A., Wojcik, E. H., Seidenberg, M. S., \& Saffran, J. R. (2013). Toddlers activate lexical semantic knowledge in the absence of visual referents: Evidence from auditory priming. Infancy, 18, 1053-1075. doi: 10.1111/infa.12026

Wojcik, E. H., \& Saffran, J. R. (2013). The ontogeny of lexical networks: Toddlers encode the 
relationships among referents when learning novel words. Psychological Science, 24, 1898-1905. doi: 10.1177/0956797613478198

Wojcik, E. H., \& Saffran, J. R. (2015). Toddlers encode similarities among novel words from meaningful sentences. Cognition, 138, 10-20. doi: 10.1016/j.cognition.2015.01.015

Wojcik, E. H., \& Werker, J. (2017, April). The effect of vocabulary size and language exposure on the emergence of monolingual and bilingual toddlers' semantic networks. Paper presented at the Biennial Meeting of the Society for Research on Language Development, Austin, TX. 


\section{SEMANTIC PRIMING IN BILINGUAL CHILDREN}

\section{Table 1}

Children's proportion of looking to the target image by condition

\begin{tabular}{|c|c|c|c|c|c|c|c|c|c|c|}
\hline Study & Months & Language group & Target relative to prime & Prime dominance & Relatedness & $M$ & $S D$ & $t$ & $d f$ & $p$ \\
\hline 1 & 24 & Monolingual English & Within-language & Dominant prime & Related & 0.56 & 0.09 & 3.28 & 19 & $0.0039 *$ \\
\hline 1 & 24 & Monolingual English & Within-language & Dominant prime & Unrelated & 0.54 & 0.11 & 1.45 & 19 & 0.16 \\
\hline 1 & 24 & Monolingual French & Within-language & Dominant prime & Related & 0.55 & 0.09 & 2.51 & 19 & $0.021 *$ \\
\hline 1 & 24 & Monolingual French & Within-language & Dominant prime & Unrelated & 0.51 & 0.07 & 0.78 & 19 & 0.45 \\
\hline 2 & 24 & Bilingual & Within-language & Dominant prime & Related & 0.57 & 0.08 & 3.62 & 15 & $0.0025 *$ \\
\hline 2 & 24 & Bilingual & Within-language & Dominant prime & Unrelated & 0.55 & 0.11 & 1.71 & 15 & 0.11 \\
\hline 2 & 24 & Bilingual & Within-language & Non-dominant prime & Related & 0.59 & 0.1 & 3.58 & 15 & $0.0028 *$ \\
\hline 2 & 24 & Bilingual & Within-language & Non-dominant prime & Unrelated & 0.56 & 0.09 & 2.54 & 15 & $0.022 *$ \\
\hline 3 & 30 & Bilingual & Within-language & Dominant prime & Related & 0.63 & 0.16 & 3.18 & 15 & $0.0063 *$ \\
\hline 3 & 30 & Bilingual & Within-language & Dominant prime & Unrelated & 0.53 & 0.15 & 0.78 & 15 & 0.45 \\
\hline 3 & 30 & Bilingual & Within-language & Non-dominant prime & Related & 0.56 & 0.24 & 1.05 & 15 & 0.31 \\
\hline 3 & 30 & Bilingual & Within-language & Non-dominant prime & Unrelated & 0.48 & 0.15 & -0.56 & 15 & 0.58 \\
\hline 3 & 30 & Bilingual & Across-language & Dominant prime & Related & 0.64 & 0.2 & 2.87 & 15 & $0.012 *$ \\
\hline 3 & 30 & Bilingual & Across-language & Dominant prime & Unrelated & 0.49 & 0.25 & -0.11 & 15 & 0.92 \\
\hline 3 & 30 & Bilingual & Across-language & Non-dominant prime & Related & 0.61 & 0.24 & 1.89 & 15 & $0.079 \dagger$ \\
\hline 3 & 30 & Bilingual & Across-language & Non-dominant prime & Unrelated & 0.49 & 0.17 & -0.14 & 15 & 0.89 \\
\hline
\end{tabular}

$* p<.05$

$\dagger p<.10$ 

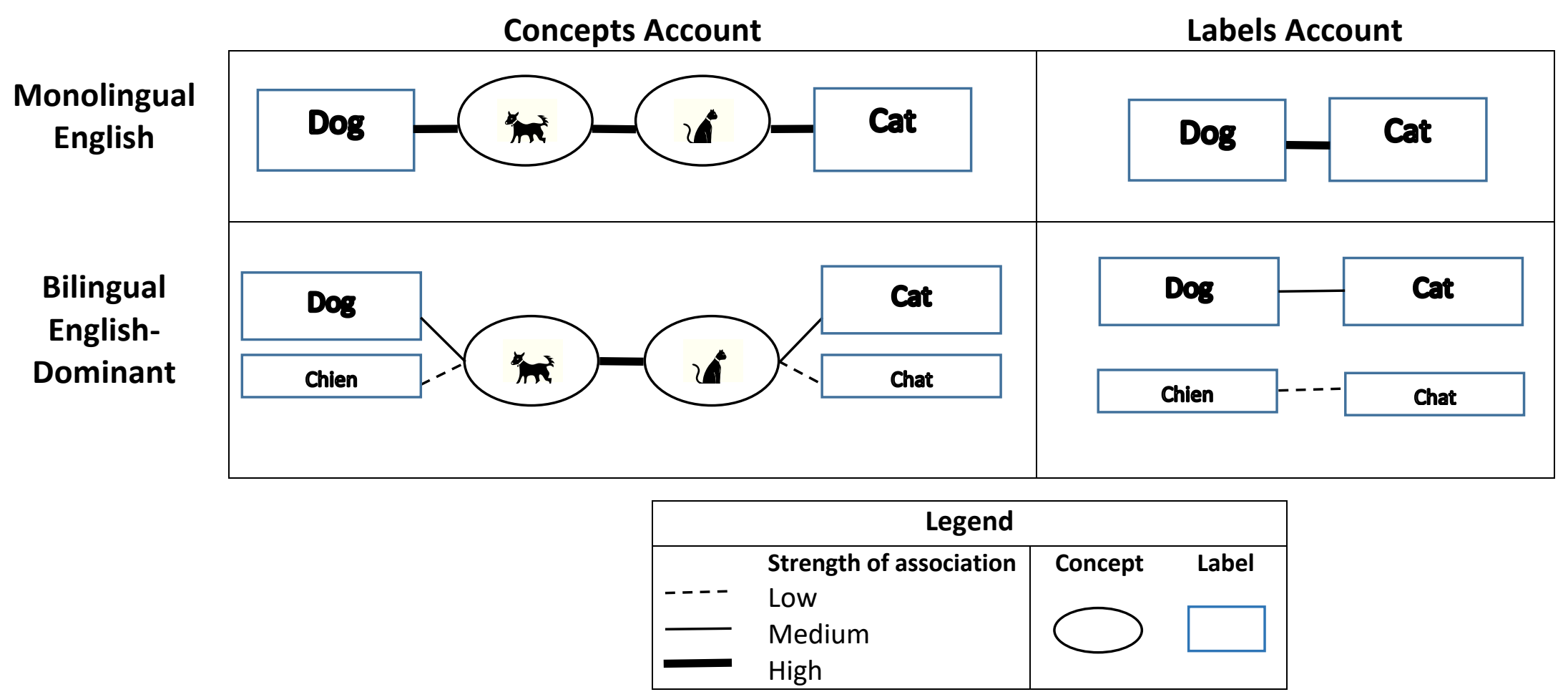

Figure 1. Two competing accounts explaining the development of semantic networks, and predictions about semantic priming. Under the Concepts account, priming occurs due to the direct links between concepts (e.g., Dog and Cat, represented as ovals). This link is strengthened whenever the concepts are activated, either via hearing the label that names that concept ("Dog": monolinguals) or hearing one of two different labels that name the concept ("Dog" and "Chien": bilinguals). The strength of association of this key link is unaffected by bilingualism or language dominance, as it is dependent only on encountering and activating particular concepts. Under the Labels account, priming occurs via direct links between labels (represented as rectangles) and is not mediated by conceptual representations. For example, the link between the labels "Dog" and "Cat" is strengthened whenever these particular labels are heard, but in the case of bilinguals is not strengthened when hearing the labels in the other language. Because bilinguals' experience with labels is divided between their two languages, at a given point in early development, label-label links will be weaker on average than those of monolinguals. Moreover, this account predicts stronger priming in the dominant than the non-dominant language, due to differences in relative experience between the labels in each of these languages. Finally, this account predicts stronger priming when the prime and target are in the same language than different languages, because same-language labels co-occur more often than different-language labels resulting in a higher strength of association within languages than across languages. 


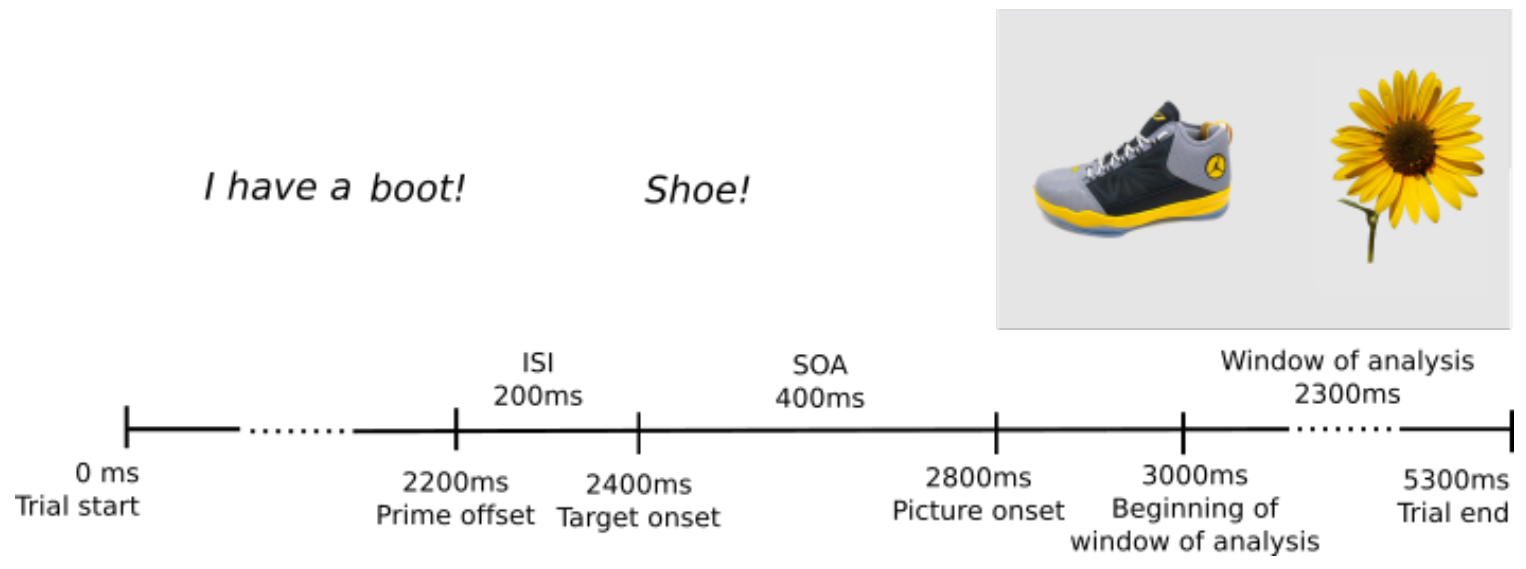

Figure 2. Schematic timeline of experimental procedure. ISI is the Inter-Stimulus Interval. SOA is the Stimulus Onset Asynchrony. Note that the diagram is for illustrative purposes and is not drawn to scale. 
SEMANTIC PRIMING IN BILINGUAL CHILDREN

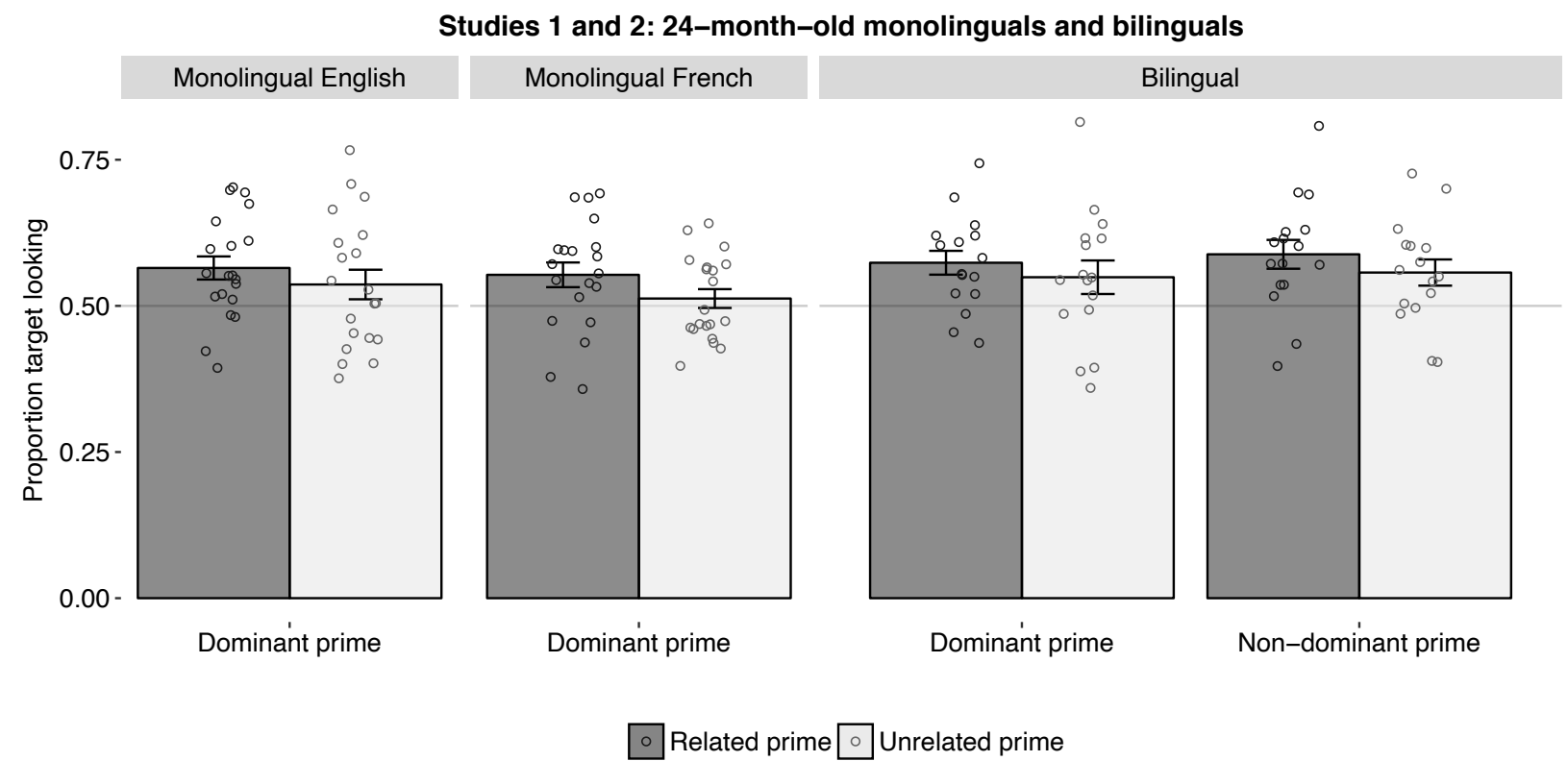

Figure 3. Children's looking towards the target object by language group (Monolingual English, Monolingual French, Bilingual), dominance (bilinguals only), and relatedness (related prime, unrelated prime) in Studies 1 and 2. Error bars represent the standard error of the mean. 


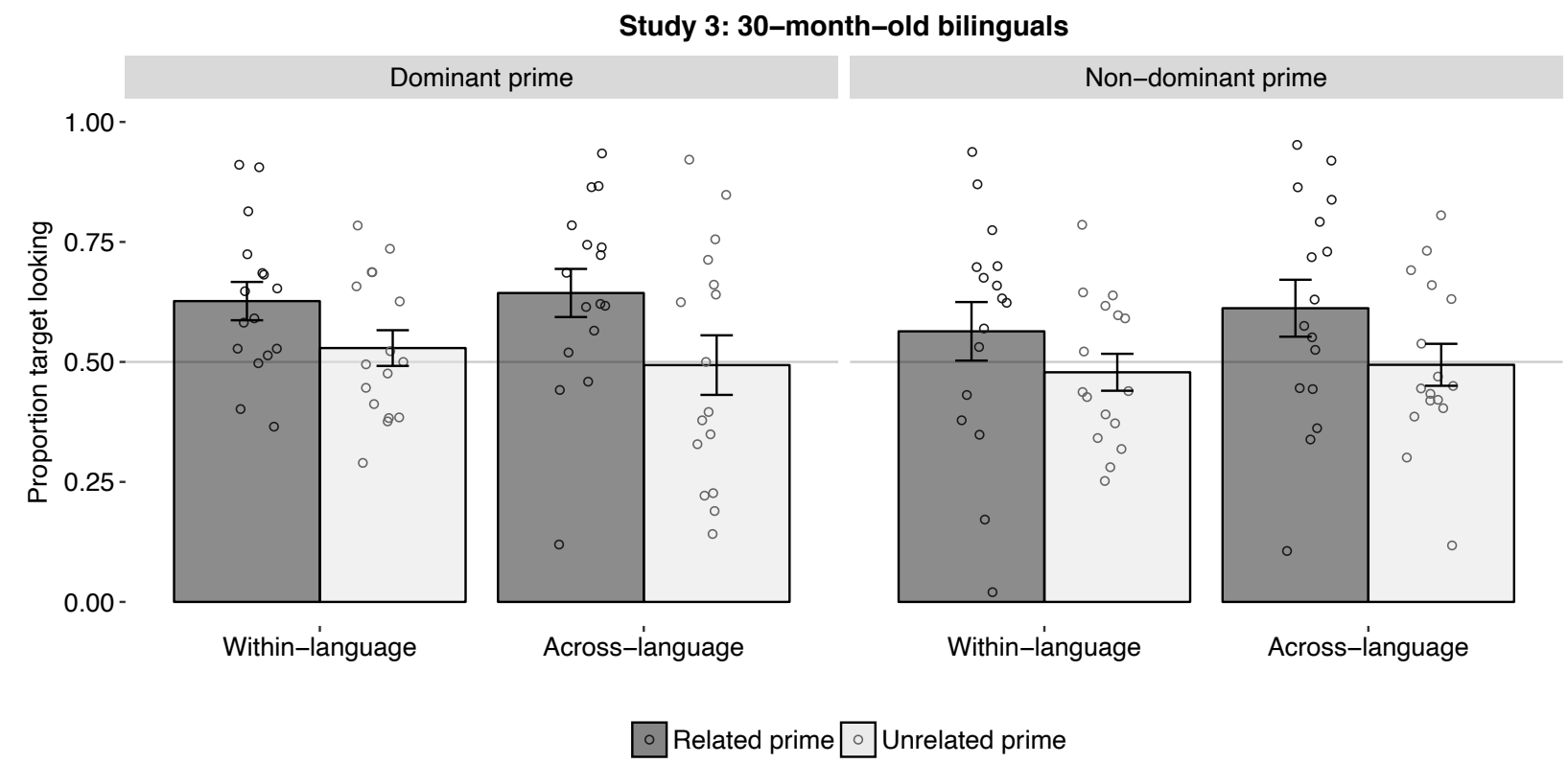

Figure 4: Children's proportion of looking to the target image by prime language (dominant vs. non-dominant language), the target language relative to the prime (within-language vs. across languages), and relatedness (related vs. unrelated). Error bars represent the standard error of the mean. 
SEMANTIC PRIMING IN BILINGUAL CHILDREN

\section{Appendix A}

Productive vocabulary size by group

\begin{tabular}{|c|c|c|c|}
\hline & Mean & $\mathrm{SD}$ & Range \\
\hline \multicolumn{4}{|c|}{ 24-month-old Monolingual English (Study 1) } \\
\hline Total vocabulary size & 374 & 142 & $165-671$ \\
\hline \multicolumn{4}{|c|}{ 24-month-old Monolingual French (Study 1) } \\
\hline Total vocabulary size & 240 & 161 & $45-536$ \\
\hline \multicolumn{4}{|c|}{ 24-month-old Bilingual French-English (Study 2) } \\
\hline Dominant-language vocabulary & 165 & 146 & $22-529$ \\
\hline $\begin{array}{l}\text { Non-dominant-language } \\
\text { vocabulary }\end{array}$ & 119 & 98 & $20-379$ \\
\hline Total vocabulary & 285 & 242 & $42-908$ \\
\hline Total conceptual vocabulary & 204 & 152 & $33-573$ \\
\hline Translation equivalents & 81 & 92 & $9-335$ \\
\hline \multicolumn{4}{|c|}{ 30-month-old Bilingual French-English (Study 3) } \\
\hline Dominant-language vocabulary & 342 & 189 & $51-632$ \\
\hline $\begin{array}{l}\text { Non-dominant-language } \\
\text { vocabulary }\end{array}$ & 133 & 121 & $23-466$ \\
\hline Total vocabulary & 475 & 255 & 74-964 \\
\hline Total conceptual vocabulary & 343 & 193 & $55-640$ \\
\hline Translation equivalents & 109 & 104 & $19-393$ \\
\hline
\end{tabular}




\section{Appendix B}

Prime-target pairs in Studies 1 and 2

\begin{tabular}{|c|c|c|c|c|}
\hline $\begin{array}{l}\text { Carrier } \\
\text { Phrase }\end{array}$ & $\begin{array}{l}\text { Prime } \\
\text { Word }\end{array}$ & $\begin{array}{c}\text { Target Word/ } \\
\text { Object }\end{array}$ & $\begin{array}{c}\text { Distractor } \\
\text { Object }\end{array}$ & $\begin{array}{c}\text { Prime-Target } \\
\text { Relatedness }\end{array}$ \\
\hline \multicolumn{5}{|c|}{ Version $\mathbf{A}$} \\
\hline I have a & Boot & Shoe & Flower & Related \\
\hline I want a & Truck & Car & Baby & Related \\
\hline I saw a & Sheep & Cow & Book & Related \\
\hline I have a & Hand & Foot & Glasses & Related \\
\hline I saw a & Door & Window & Sock & Related \\
\hline I want a & Bowl & Spoon & Cat & Related \\
\hline I have a & Shirt & Banana & Ear & Unrelated \\
\hline I want a & Chair & Train & Eyes & Unrelated \\
\hline I want an & Apple & Horse & Telephone & Unrelated \\
\hline I saw a & Bus & Mouth & Slide & Unrelated \\
\hline I have a & Nose & Pants & Ball & Unrelated \\
\hline I saw a & Pig & Table & Cookie & Unrelated \\
\hline \multicolumn{5}{|c|}{ Version B } \\
\hline I have a & Hand & Shoe & Flower & Unrelated \\
\hline I saw a & Sheep & Car & Baby & Unrelated \\
\hline I saw a & Door & Cow & Book & Unrelated \\
\hline I want a & Bowl & Foot & Glasses & Unrelated \\
\hline I want a & Truck & Window & Sock & Unrelated \\
\hline I have a & Boot & Spoon & Cat & Unrelated \\
\hline I want an & Apple & Banana & Ear & Related \\
\hline I saw a & Bus & Train & Eyes & Related \\
\hline I saw a & Pig & Horse & Telephone & Related \\
\hline I have a & Nose & Mouth & Slide & Related \\
\hline I have a & Shirt & Pants & Ball & Related \\
\hline I want a & Chair & Table & Cookie & Related \\
\hline
\end{tabular}

Note: This list does not reflect the order of presentation of trials during testing. 
Appendix C

Prime-target pairs in Study 3

\begin{tabular}{|c|c|c|c|c|c|}
\hline $\begin{array}{l}\text { Carrier } \\
\text { Phrase }\end{array}$ & $\begin{array}{l}\text { Prime } \\
\text { Word }\end{array}$ & $\begin{array}{c}\text { Target Word/ } \\
\text { Object }\end{array}$ & $\begin{array}{c}\text { Distractor } \\
\text { Object }\end{array}$ & $\begin{array}{c}\text { Prime-Target } \\
\text { Relatedness }\end{array}$ & $\begin{array}{l}\text { Target by } \\
\text { Language }\end{array}$ \\
\hline \multicolumn{6}{|c|}{ Version A } \\
\hline I like that & Horse & Cow & Banana & Related & Within \\
\hline I saw a & Window & Door & Frog & Related & Within \\
\hline I want a & Scarf & Coat & Truck & Related & Within \\
\hline I found a & Plate & Ear & Chair & Unrelated & Within \\
\hline I have a & Foot & Spoon & Flower & Unrelated & Within \\
\hline I have two & Eyes & Sock & Bed & Unrelated & Within \\
\hline \multicolumn{6}{|c|}{ Version B } \\
\hline I like that & Horse & Vache & Banana & Related & Across \\
\hline I saw a & Window & Porte & Frog & Related & Across \\
\hline I want a & Scarf & Manteau & Truck & Related & Across \\
\hline I found a & Plate & Oreille & Chair & Unrelated & Across \\
\hline I have a & Foot & Cuillère & Flower & Unrelated & Across \\
\hline I have two & Eyes & Bas & Bed & Unrelated & Across \\
\hline
\end{tabular}

Note: This list does not reflect the order of presentation of trials during testing. 